\title{
Earnings after Dl: evidence from full medical continuing disability reviews
}

Jeffrey Hemmeter ${ }^{*}$ and Michelle Stegman Bailey

\author{
* Correspondence: \\ jeffrey.hemmeter@ssa.gov \\ Office of Research, Demonstration, \\ and Employment Support, Social \\ Security Administration, 3707a RMB \\ Building, 6401 Security Blvd., \\ Baltimore, MD 21235, USA
}

\begin{abstract}
Social Security Disability Insurance beneficiaries undergo periodic medical reviews to determine if they continue to be eligible for disability benefits. We examine how these reviews affect beneficiary well-being by using administrative data to track the earnings of beneficiaries for up to 5 years after their reviews. We estimate that a sizeable percentage of beneficiaries would work if their benefits were ceased in a medical review. However, many appear to be unable to maintain employment: only one in three would have earnings over the full follow-up period. Further, far fewer would reach any of several measures of earnings sufficiency.
\end{abstract}

JEL codes: H51, H53, I38, J14

Keywords: Disability Insurance, Continuing disability review, Earnings

\section{Introduction}

In recent decades, spending on Social Security Disability Insurance (DI) worker benefits has increased due to an increase in the number of awards coupled with the length of time beneficiaries remain on the rolls. ${ }^{1}$ This increase in program costs has led to calls for stronger program oversight including tighter controls on program entry (see Morton 2015 for a review of various proposals) and helping current beneficiaries return to work (e.g., Social Security Advisory Board 2009; DeHaven 2013). One way to address this issue is to increase the number of post-award medical reviews that the Social Security Administration (SSA) conducts to determine whether beneficiaries remain eligible for the program. Whether SSA should increase the number of medical reviews depends on factors such as the potential program savings, the cause of the increase in the number of benefit awards in recent years, and the economic outcomes for beneficiaries removed from the rolls as a result of a medical review. We focus on the last point by examining the earnings of former beneficiaries, which we interpret as a plausible upper bound on the potential earnings that beneficiaries who remain eligible for the program could attain if their eligibility were hypothetically to cease.

In conducting medical reviews, SSA identifies some beneficiaries as no longer eligible, thereby saving the cost of future benefits that would have been paid to those individuals. Medical reviews can be very expensive; but even during the government sequestration in 2013, the president's budget called for an increase in program integrity, including the number of post-award medical reviews conducted by SSA to ensure 
beneficiaries remain eligible for the program. SSA estimated that for each $\$ 1$ spent on these reviews approximately $\$ 13.2$ in net Federal lifetime benefits (including Old Age, Survivors, and Disability Insurance, Supplemental Security Income, Medicare, and Medicaid) were saved in FY 2011 (SSA 2013a), though there are different returns on investment by type of disability program (Stephens, 2014). The high average return suggests that SSA could conduct more reviews and save more in lifetime benefits, although these savings would outweigh the costs only up to a certain point.

Many have suggested that the increase in the number of beneficiaries is driven by the attractiveness of the disability programs relative to the job opportunities for workers with disabilities (e.g., Autor and Duggan 2006) and an increase in the number of applicants with harder-to-establish conditions such as musculoskeletal and mental impairments (e.g., Burkhauser and Daly 2011, 2012). However, others suggest that this increase is primarily a byproduct of an aging population and other demographic changes, such as the increasing proportion of women working and gaining insured status for DI (Goss, 2013). Identifying the cause of this increase is important and may have implications for any increase in the frequency or number of medical reviews. For instance, a higher proportion of beneficiaries with less easily verifiable conditions means that increased reviews will, in addition to removing beneficiaries who are no longer medically eligible, inevitably remove some who should remain eligible due to inherent uncertainties associated with their condition.

The effectiveness of conducting medical reviews depends in part on the fraction of beneficiaries on the rolls with the ability to work at a substantial level. The idea that many of the people receiving disability benefits would be gainfully employed in the absence of these programs has a long, if controversial, history. Parsons (1980), for example, argued that the reduction in labor force participation of working-age males was "largely explained by the increased generosity of social welfare transfers, particularly Social Security disability payments" (p. 130), and Black, Daniel, and Sanders (2002), Autor and Duggan (2003), and others have made similar points. Bound (1989), on the other hand, argued that an upper bound on the percent of older men receiving DI benefits in the 1970s who would work in the absence of DI was less than $50 \%$.

Although not without detractors (notably Parsons 1991), Bound's conclusions have been validated for a variety of other populations and years (see, for example, Chen and van der Klaaw 2008 and von Wachter, Song, and Manchester 2011). The increase in the proportion of younger applicants, and a higher likelihood of work among younger rejected applicants, has contributed to a gradual increase in Bound's estimated upper limit on employment among DI beneficiaries (von Wachter, Song, and Manchester 2011). Other recent studies have used instrumental variables to predict the employment impacts of DI (see Maestas, Mullen, and Strand (2013) and French and Song (2014), for example). These studies are similar in concept to the Bound approach but support a more causal interpretation and find somewhat larger impacts on employment than Bound.

While informative about the effect of the disability program on labor supply and earnings of the population, most studies have not typically provided information on the potential loss of benefits on the existing beneficiary population. This difference is subtle but important. Current beneficiaries are even more likely than applicants to suffer from human capital depreciation and weakened social and employment networks, resulting in larger barriers to employment. Brucker (2015), for example, found that individuals 
with disabilities in the labor force had higher levels of social capital than those with disabilities not in the labor force. Individuals removed from DI have been out of the labor force for several years and would thus be expected to have lower levels of social capital. Nichols et al. (2013), however, review the consequences of long-term unemployment, many of which would be expected to be relevant for individuals receiving DI and amplified by the presence of a disability, and find little evidence to explain exactly how these consequences lead to worse outcomes. If current beneficiaries are substantially less employable than applicants, the employment impacts of ceasing beneficiaries from the program may be smaller than those of tightening front-end eligibility.

There has been some research on DI beneficiaries who medically recover (e.g., Dykacz 1998; Hennessey and Dykacz 1993; Dykacz and Hennessey 1989; Treitel 1979; Schmulowitz 1973), but these studies do not look at the subsequent earnings. Moore (2014) analyzed SSA's elimination of drug abuse and alcoholism as a qualifying disability in the mid-1990s and found a large employment effect just after the termination of individuals with these diagnoses, but the effect declined over time. Moore's findings result from a unique change in policy-removing a specific disability category-and may not reflect the general population of disability beneficiaries.

Internationally, there is mixed evidence that tightening disability program eligibility rules impacts labor supply. Staubli (2011), for example, found that tightening the eligibility for Austria's disability insurance program increased employment. Conversely, Karlström, Palme, and Svensson (2008) found that a disability insurance rule change in Sweden had little impact on employment but did increase the use of other social services. Similarly, Borghans, Gielen, and Luttmer (2014) find that when benefits were decreased in the Netherlands, individuals often turned to other social services. However, they also found that many long-term disability recipients were capable of work at substantial levels. ${ }^{2}$

In this paper, we extend Bound's approach and examine the subsequent earnings of beneficiaries who undergo a medical review, comparing outcomes between those who remain eligible for disability benefits and those who do not, which we refer to as the exit margin. Whereas Bound (and subsequent researchers) used the earnings of denied applicants as the upper limit on the potential lost earnings and employment of allowed DI applicants, we use the earnings of beneficiaries whose program eligibility ceases because of a medical review as an upper limit on the potential earnings of beneficiaries who continue on the program. SSA refers to these medical reviews as continuing disability review (CDRs), and we describe individuals as "ceased" if SSA determines in a CDR that they are no longer eligible for disability benefits.

Although ceased individuals do not meet the medical standards for DI, it does not follow that they are able to earn at a level that would enable them to be self-sufficient for a sustained period. Indeed, the annual earnings in 2014 considered to qualify as substantial gainful activity (SGA) are only $\$ 1170$ more than the 2014 poverty guideline for an individual over 12 months. An open question is whether individuals who lose eligibility for disability benefits are able to earn enough to avoid poverty. We provide some evidence of their earning capacity by comparing their post-cessation earnings with their pre-eligibility earnings and with measures of their potential benefit, the federal minimum wage, the SGA level, and the individual poverty guideline.

In brief, we find that the majority of ceased DI workers have earnings after program exit. For obvious reasons, individuals who remain eligible for benefits are less likely 
to seek employment than they would if they were ceased; for that group, we estimate an upper bound for the likelihood of having earnings of about 43 percentage points if they were ceased. Average earnings are generally low, only $\$ 13,000$. Additionally, while over half of ceased DI workers earn above the SGA level or the individual poverty threshold in at least one of the 5 years after program exit, only about $20 \%$ consistently earn over SGA or the poverty threshold in all post-program years.

\section{SSA disability policy}

For an adult to be eligible for DI, he or she must be unable to engage in SGA by reason of any medically determinable physical or mental impairment that is expected to result in death or to last for a continuous period of at least 12 months. Factors such as age, education, the ability to do prior work, and the ability to perform other jobs in the national economy can also be considered when determining whether a person has a disability that qualifies for the program.

To be insured for DI benefits, an individual must have a sufficient and recent work history, measured in quarters of coverage or work credits, in a covered job to meet eligibility requirements. Each year, the level of earnings required for one quarter of coverage changes; in 2016, it was $\$ 1260$. An individual can earn up to four quarters of coverage per year. Although the number of quarters required for eligibility varies by age at disability onset, an individual generally needs a minimum of six quarters of coverage plus an additional quarter for each year after attaining age 22, with a maximum requirement of 40 quarters of coverage. For those over the age of 30 at disability onset, individuals must have earned at least 20 quarters of coverage during the 10 years prior to onset. $^{3}$

SSA also operates the Supplemental Security Income (SSI) program, for which DI beneficiaries may also be eligible. ${ }^{4}$ While the adult eligibility criteria for the SSI program include the same definition of disability as the DI program, there is no work history requirement, but individuals can have no more than $\$ 2000$ in resources (or $\$ 3000$ for couples, if both members are eligible.) Additionally, there are residency, citizenship, and other requirements for SSI. Eligible individuals receive the Federal benefit rate (\$721 in 2014) plus any state supplements, less any countable income. Unearned income, such as DI benefits, reduces SSI payments dollar for dollar after an initial disregard of the first $\$ 20$ of unearned income.

DI beneficiaries can earn any amount of money during a rolling 9-month trial work period every 60 months. If they earn more than SGA after the trial work period, they enter a 36-month extended period of eligibility during which they may receive benefits for each month they do not work above SGA. If they have earnings above SGA at the end of this period, their eligibility is terminated but can be reinstated expeditiously during the following 5 years. Beneficiaries can also take advantage of many work incentives designed to minimize the impact of returning to work on benefits.

\subsection{The medical CDR process ${ }^{5}$}

Despite SSA's work incentives and return-to-work programs, DI is designed for those with disabilities that substantially limit the ability to work. To ensure that only eligible individuals remain on the program, SSA reviews several hundred thousand cases each 
year looking for medical improvement since the last favorable eligibility determination (i.e., the initial allowance for first-time CDRs or the most recent CDR continuation for subsequent CDRs). Medical CDRs are mandated by law, though SSA has some discretion in how to administer them. The date for a CDR, known as a diary date, is set at the time benefits are awarded, and a new diary date is set at each subsequent favorable decision. These diary dates range from 6 months to 7 years, depending on the likelihood of medical improvement.

Each year, SSA uses a profiling model controlling for various demographic and programmatic characteristics to determine whether to send a case through the full medical review (FMR) process (known as a "direct release") or to mail the beneficiary a questionnaire asking for more information (known as a "mailer"). The model generates a score for each beneficiary, with higher scores corresponding to a greater likelihood of medical improvement. Cases with high scores that are due (or overdue) for a review are typically sent directly through the FMR process whereas corresponding medium and low-scoring cases receive the mailer questionnaire first. Beneficiaries who receive mailers are asked to provide SSA with more information about their current medical status and their ability to work. Cases with mailer responses that show an indication of medical improvement are in turn sent through the FMR process. If there is no indication of medical improvement in the responses, the beneficiary continues on the program, and a new diary date is set for the next review.

For mailer responses indicating an FMR is necessary, as well as for those directly released for an FMR, the state Disability Determination Services (DDS) gathers relevant information to make a determination. If there is sufficient evidence of medical improvement since the last favorable decision, the beneficiary receives a cessation decision. This decision can be appealed to several levels-a reconsideration at the DDS, an administrative law judge (ALJ) review, an Appeals Council review, and ultimately a review in the Federal courts. If there is insufficient evidence of medical improvement since the last favorable decision, the beneficiary continues on the program and a new CDR diary date is set. ${ }^{6}$

\subsection{CDR workload}

The number of CDRs that SSA is able to perform in a given year is driven in part by the amount budgeted for CDR processing and the staff qualified to process them. Between 1998 and 2008, annual funding for all centrally initiated SSI and DI CDRs ranged from about $\$ 300$ million to almost $\$ 800$ million measured in 2012 dollars (Fig. 1). Congress has occasionally designated funding explicitly for CDRs. For example, the Contract with America Advancement Act and the Personal Responsibility and Work Opportunity Reconciliation Act provided dedicated funding from 1996 through 2002 to meet new CDR and age-18 redetermination requirements included in those acts. This funding enabled SSA to reduce the backlog and become current with medical CDRs (i.e., conduct all scheduled CDRs) by the end of FY 2002 (SSA 2013a). Funding for conducting medical CDRs declined substantially from FY 2002 levels over FYs 2003 to 2007. CDR backlogs rebounded to about 1.3 million in FY 2011 (SSA 2013a) due to this reduction in funding, although funding has increased slightly since FY 2007, measured in 2012 dollars. 


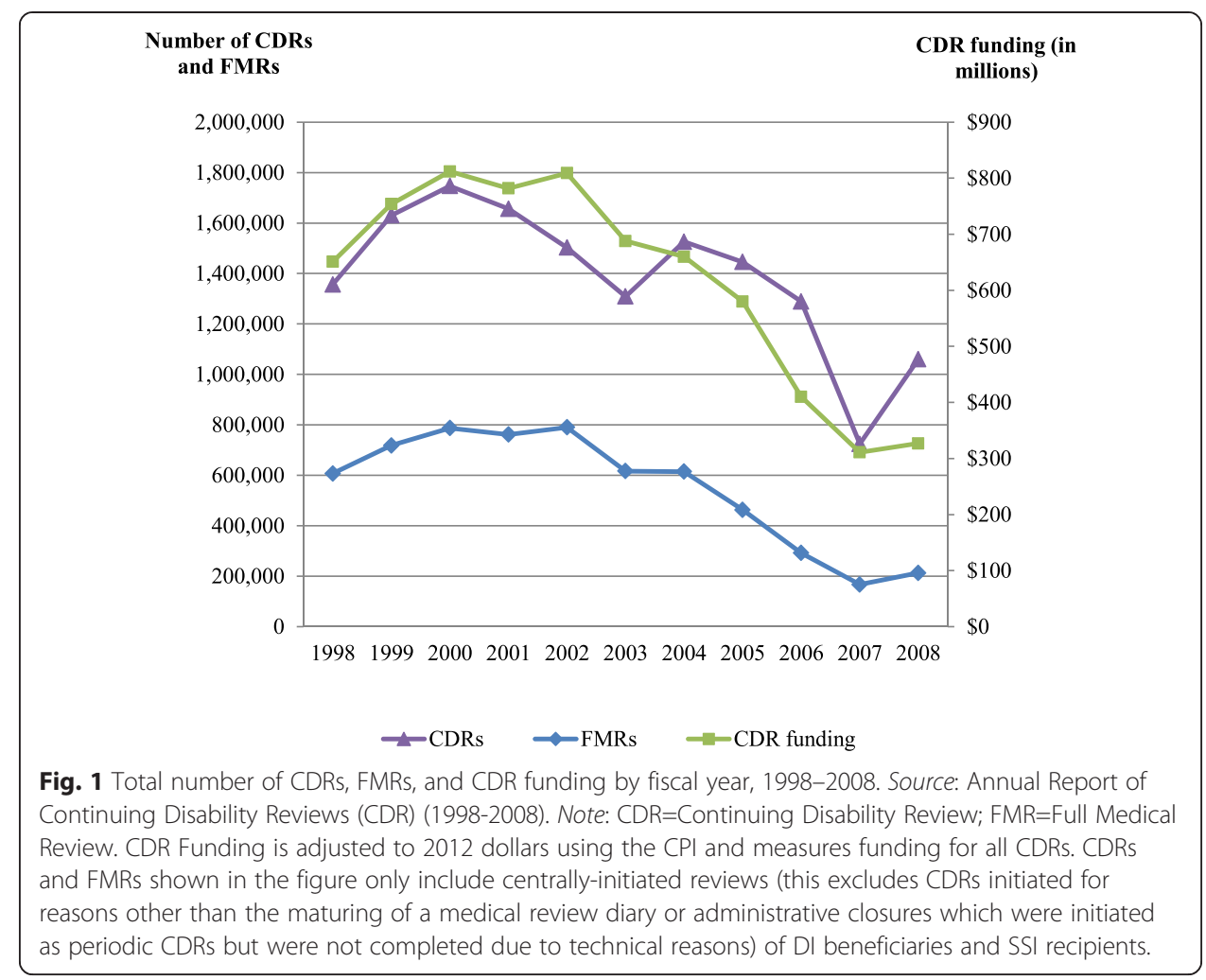

\section{Data sources}

SSA's CDR Waterfall file contains information on centrally initiated FMRs which received a DDS determination. We focus on individuals in the DI program who had an FMR from calendar years 1998 through 2008. Among other information, the Waterfall file includes date of birth, gender, date of program eligibility, the primary diagnosis prior to the FMR, diary type (medical improvement expected (MIE), possible (MIP), or not expected (MINE)), ${ }^{7}$ whether the individual received a mailer prior to the FMR, the CDR profile score, dates of the initial and final FMR decisions, and the final outcome of the FMR (continued or ceased) after all appeals.

We merged the Waterfall file with SSA's Numident file to obtain dates of death and with the Master Beneficiary Record (SSA's main records for the DI program) to replace missing dates of birth. We also used SSA's Disability Research File to determine whether an individual returns to either DI or SSI after cessation. Data for individuals who died during the study period are included in our analyses for as long as they were alive. ${ }^{8}$

Additionally, we merged the data with the Summary Earnings Record (SER) to include earnings subject to the Social Security tax. ${ }^{9}$ At the time the data was drawn, the SER was complete through 2012, providing at least 4 years of follow-up for almost all target population members. For several of our analyses, we examine mean earnings for up to 5 years before program eligibility and up to 5 years after the FMR. For example, to measure mean earnings after the final FMR determination, we took the average earnings during the 5 years after the year of the final FMR-for an individual whose final decision was in 2003, this includes earnings in 2004, 2005, 2006, 2007, and 2008. We chose 5 years because that allows for most individuals who return to work to reestablish themselves in the work force. ${ }^{10}$ For cohorts with fewer than 5 years after the 
final FMR, we use the mean earnings for all years through 2012-for an individual whose final decision was in 2008, we take the mean of earnings in 2009, 2010, 2011, and 2012. We also looked at shorter measures of earnings, including earnings in each year after the FMR, and the results are qualitatively similar. We adjust all earnings measures by the Consumer Price Index-All Urban Consumers (CPI-U) to 2012 dollars. ${ }^{11}$

\subsection{Hypotheses and outcome measures}

Similar to Bound's (1989) study of denied applicants, our results on the earnings of those who had their payments ceased due to an FMR may be interpreted as an upper limit to the potential earnings of those who remain on the program after an FMR if their eligibility had instead ceased. Theoretically, those who have their payments ceased are in better health and are therefore less likely to experience barriers in the labor market compared to those who continue to be medically eligible for the program. Hence, we can think of these estimated earnings as an upper bound of what we could expect if SSA mechanically increased the number of FMRs, within a particular CDR group, using the same selection criteria. While these individuals no longer meet the definition of disability used for SSA program eligibility, they likely continue to have barriers to employment, such as health deterioration, skill decay, and diminished social and employment networks. ${ }^{12}$ Increasing the number of FMRs would likely result in DI beneficiaries with more severe disabilities receiving those FMRs; these individuals would likely have greater labor market barriers than our target population and thus earn less.

We operationalize this hypothesis with the following regression, estimated by ordinary least squares:

$$
Y_{i}=\alpha+\beta * \operatorname{Ceased}_{i}+\sum_{j=1}^{J} \gamma_{j} * X_{i j}+\varepsilon_{i},
$$

where $Y_{i}$ is an outcome of interest, the set of which is described below; Ceased ${ }_{i}$ is a dummy variable equal to 1 if the individual was ceased and 0 if continued; $X_{i j}$ is a set of $J$ covariates $^{13} ; e_{i}$ is an error term; and $a, b$, and $g_{j}$ are parameters to be estimated.

Our outcomes of interest include whether an individual has earnings, the level of earnings, and comparisons to key earnings thresholds chosen to provide objective points of reference. For these additional earnings thresholds, we use 5-year averages to summarize the effect of the FMR cessation. While masking any potential differences in the impact from year to year, this formulation adds the convenience of providing a single estimate of the impact of the FMR for these outcomes. Supplemental data analyses (e.g., using various time measures of earnings -1 year, 2 years, etc.) indicated this loss of information is not a substantial issue. We present the predicted outcomes from Eq. (1) for all our results. These results are similar to unadjusted outcomes, which are available upon request.

The first comparison to an earnings threshold is whether post-FMR earnings are greater than pre-eligibility earnings, to determine whether individuals return to work at their prior level of earnings (as measured by their average earnings 5 years before eligibility). While we expect a decline in earnings in the few years before eligibility due to disability or job loss, we use 5-year earnings averages to mitigate this effect. The second threshold is the maximum potential benefit the individual could have received 
from SSA had he or she remained on the program and not returned to work. ${ }^{14}$ We do not use actual payments made to individuals while receiving benefits because it is not clear that the last payment or an average of recent payments would reflect the payments available to individuals had they remained on DI; any use of SSA's work incentives or other sources of income in SSA's records may be temporary.

We also measure whether post-FMR earnings are greater than the poverty threshold for a single person, an annualized equivalent of SGA (i.e., 12 times the monthly SGA), and the annualized equivalent of working full-time at the federal minimum wage level (assuming $2080 \mathrm{~h}$ a year). These last three measures provide comparative earning thresholds that are independent of the individual. Note that for the potential benefit, poverty threshold, SGA, and minimum wage comparisons, we use nominal dollar values each year. ${ }^{15}$ We do not project these values past the years available at the time of writing; as with the earnings values, they are defined as missing after 2012. Estimates include years with $\$ 0$ earnings. It is important to keep in mind that all our earnings measures only serve as proxies for an individual's well-being and do not measure family supports, other government transfers, or other sources of income and support for which the individual may be eligible or have access to.

Recent research by Maestas, Mullen, and Strand (2013) used an instrumental variables approach to estimate a causal effect of the DI program on employment. They point out (along with Parsons 1991 and others) that Bound's approach could understate the potential employment effect if the application process itself (particularly the appeals process) is a factor in the reduction of an applicant's work capacity. Our study is also subject to this possibility; however, there are two reasons it may not be as strong an objection to the methodology on the exit margin presented here. First, we are primarily interested in a substantially smaller policy counterfactual. Whereas Bound, Parsons, and others have generally been interested in the role of DI on the reduction in male employment writ large, we are instead interested in the potential impact of an increase in the number of CDRs SSA conducts. As a result, we assume the current structure of the CDR selection process will by and large stay the same, with only marginal adjustments to the selected population-including a full appeals process to which beneficiaries will be eligible. A second, related factor mitigating this methodological concern is that our follow-up period is measured from the time of the final FMR decision, when beneficiaries no longer have a reason to hold down their earnings in the anticipation of eventual program receipt. Thus, this criticism is likely of much less importance to the exit margin we examine.

\section{The target population: selection and characteristics}

The target population in this paper comprises adult DI worker beneficiaries who underwent an FMR between 1998 and 2008. It is important to note that this specific population is not representative of the entire CDR population in any given year or the population of current DI beneficiaries at any given point. Only $21.5 \%$ of DI workers selected for a CDR undergo an FMR (SSA 2013a). We include concurrent beneficiaries (i.e., beneficiaries who receive both DI and SSI) in our analyses.

We exclude beneficiaries who (1) are missing a final decision date or profile score; (2) have inconsistent dates (such as a date of eligibility prior to a date of birth); (3) died before receiving the final decision; (4) have appealed a cessation decision and are awaiting 
a new decision or still have time to appeal their cessation; (5) received a final decision after 2009; or (6) are in one of three age groups: under age 18 at the time of the initial decision, age 60 or older at the time of the initial decision, or age 62 or older at the time of the final decision. We also exclude (7) FMRs that are not the first FMR for members of our sample. Restrictions (5) and (6) ensure that we have only adults and adequate follow-up time, to avoid issues with early retirement. ${ }^{16}$ We impose restriction (7) to avoid overlap between two FMRs. These exclusions lead to a target population of $2,124,835$ DI workers with each person only appearing at most once.

\subsection{DI worker beneficiary characteristics}

In Table 1, we present selected characteristics of ceased and continued DI workers who had an FMR between the calendar years of 1998 and 2008. Compared to the full DI worker population in 2008 (not shown), our sample is more likely to be in their 30s

Table 1 Personal characteristics, percentage distribution by FMR outcome, and final cessation rate for DI workers

\begin{tabular}{|c|c|c|c|c|c|}
\hline & \multicolumn{2}{|l|}{ Total } & \multirow{2}{*}{$\begin{array}{l}\text { Continued } \\
\text { (\%) }\end{array}$} & \multirow{2}{*}{$\begin{array}{l}\text { Ceased } \\
(\%)\end{array}$} & \multirow{2}{*}{$\begin{array}{l}\text { Cessation rate } \\
\text { (row \%) }\end{array}$} \\
\hline & $\%$ & $\mathrm{~N}$ & & & \\
\hline Total & 100.0 & $2,124,835$ & 100.0 & 100.0 & 5.7 \\
\hline \multicolumn{6}{|l|}{ Age at initial FMR decision } \\
\hline 18 to 30 & 5.6 & 119,920 & 5.2 & 13.2 & 13.4 \\
\hline 30 to 39 & 22.4 & 475,571 & 21.8 & 32.7 & 8.4 \\
\hline 40 to 49 & 41.3 & 878,587 & 41.5 & 39.4 & 5.5 \\
\hline 50 to 59 & 30.6 & 650,757 & 31.6 & 14.7 & 2.8 \\
\hline \multicolumn{6}{|l|}{ Primary diagnosis } \\
\hline Infectious and parasitic diseases & 0.6 & 13,505 & 0.6 & 0.5 & 4.3 \\
\hline Neoplasms & 2.7 & 56,511 & 2.3 & 8.2 & 17.6 \\
\hline Endocrine, nutritional, and metabolic diseases & 4.3 & 92,185 & 4.4 & 2.7 & 3.5 \\
\hline Blood and blood-forming organs diseases & 0.4 & 7844 & 0.3 & 0.8 & 12.1 \\
\hline Other mental disorders & 29.0 & 615,212 & 28.9 & 30.6 & 6.0 \\
\hline Schizophrenia and other psychotic disorders & 7.9 & 167,896 & 7.9 & 7.8 & 5.6 \\
\hline Intellectual disabilities & 3.8 & 80,547 & 3.8 & 3.0 & 4.5 \\
\hline Nervous system and sense organs diseases & 8.5 & 181,598 & 8.7 & 6.0 & 4.0 \\
\hline Circulatory system diseases & 5.9 & 126,250 & 6.0 & 4.5 & 4.3 \\
\hline Respiratory system diseases & 1.7 & 36,363 & 1.7 & 1.6 & 5.3 \\
\hline Digestive system diseases & 2.1 & 45,286 & 2.1 & 3.5 & 9.5 \\
\hline Genitourinary system diseases & 1.7 & 37,164 & 1.6 & 3.9 & 12.9 \\
\hline Skin and subcutaneous tissue diseases & 0.4 & 7505 & 0.4 & 0.4 & 6.5 \\
\hline Musculoskeletal system and connective tissue diseases & 19.7 & 418,955 & 20.0 & 14.4 & 4.2 \\
\hline Congenital anomalies & 0.2 & 4267 & 0.2 & 0.1 & 3.8 \\
\hline Other & 6.4 & 136,807 & 6.3 & 9.2 & 8.2 \\
\hline Injuries & 0.1 & 2887 & 0.1 & 0.1 & 6.1 \\
\hline Unknown & 4.4 & 94,053 & 4.5 & 2.8 & 3.6 \\
\hline N & \multicolumn{2}{|c|}{$2,124,835$} & $2,003,363$ & 121,472 & \\
\hline
\end{tabular}

Source: Authors' calculations using Social Security administrative records Note: FMR full medical review. See text for full descriptions of the sample 
and 40s and less likely to be in their 50s. Our sample also has a higher proportion of individuals with mental impairments other than intellectual disabilities, endocrine, nutritional, and metabolic diseases, other and unknown diagnoses, and a smaller proportion of individuals with circulatory system diseases compared to all DI workers in 2008 (SSA 2009).

The final cessation rate, accounting for all appeals through the time of data extraction, is $5.7 \%$ for DI workers, although this rate varies greatly within some characteristic groups. We find notably higher cessation rates among younger beneficiaries in our population. For example, DI workers age 18 to 30 have a $13 \%$ cessation rate compared to less than $3 \%$ for workers age 50 to 59 . This can also be seen in the age distribution of the continued and ceased groups, where the ceased group has a much larger proportion of younger DI workers than the continued group. Some of the largest differences in cessation rates occur within primary diagnosis categories. We see relatively high cessation rates for those with neoplasms (18\%), and diseases of the genitourinary system (13\%), and low cessation rates in the congenital anomalies and endocrine, nutritional, and metabolic systems diseases categories (less than $4 \%$ ). There may be substantial differences in the employment outcomes by these groups. Prior research has shown that the employment and earnings of beneficiaries vary greatly by impairment type (Mann et al. 2015). Additionally, there may be large differences within impairment groups, as younger beneficiaries have been shown to have better employment outcomes in general (Ben-Shalom and Mamun 2015). However, we do not hypothesize who will be more or less able to return to their prior field of employment or benefit more from existing support structures.

DI workers who received a mailer prior to their FMR have a lower cessation rate than to those who were directly released (Table 2). As would be expected, the ceased group has a higher proportion of MIE diary types, who SSA deemed more likely to medically improve at the time of their last favorable decision. Beneficiaries with high profile scores have a final cessation rate more than twice the rate for low- and mediumscoring beneficiaries. There is no distinguishable pattern in cessation rates across FMR years for our population, other than slightly higher rates in the later years when fewer FMRs were conducted, a finding we return to later in the paper.

\section{Estimates of cessation impact on earnings outcomes}

Consistent with the program's focus on replacing lost wages due to disability, earnings fall steeply in the year just before eligibility (Fig. 2). While those who continue to receive benefits after the FMR expectedly have low mean earnings, those who are ceased typically do not return to their pre-DI earnings levels. On average, former DI workers only reach about $70 \%$ of their pre-DI earnings levels-dropping from about $\$ 19,000$ in the 5 years before eligibility to about $\$ 13,000$ in the 5 years after the FMR (Table 3).

Controlling for other characteristics, we estimate that, in the 5 years after the FMR, former beneficiaries earn roughly $\$ 11,000$ more (per year) than those continued on the program (Table 3). Almost $70 \%$ of ceased beneficiaries have earnings during the 5 years after the FMR, compared to about a quarter of continued beneficiaries. All else equal, ceased beneficiaries are about 45 percentage points more likely than their continued peers to have earnings above SGA, the poverty level, or the full-time minimum wage in the 5 years after the FMR (over a predicted base rate of about $6-7 \%$ for those 
Table 2 CDR characteristics, percentage distribution by FMR outcome, and final cessation rate for DI workers

\begin{tabular}{|c|c|c|c|c|c|}
\hline & \multicolumn{2}{|l|}{ Total } & \multirow{2}{*}{$\begin{array}{l}\text { Continued } \\
(\%)\end{array}$} & \multirow{2}{*}{$\begin{array}{l}\text { Ceased } \\
(\%)\end{array}$} & \multirow{2}{*}{$\begin{array}{l}\text { Cessation rate } \\
\text { (row \%) }\end{array}$} \\
\hline & $\%$ & $\mathrm{~N}$ & & & \\
\hline Total & 100.0 & $2,124,835$ & 100.0 & 100.0 & 5.7 \\
\hline \multicolumn{6}{|l|}{ CDR diary type } \\
\hline MIE & 18.9 & 400,820 & 18.5 & 24.8 & 7.5 \\
\hline MIP & 71.8 & $1,526,419$ & 71.9 & 70.4 & 5.6 \\
\hline MINE & 9.3 & 197,596 & 9.6 & 4.9 & 3.0 \\
\hline \multicolumn{6}{|l|}{ CDR release type } \\
\hline Direct release & 81.5 & $1,731,979$ & 81.2 & 86.1 & 6.0 \\
\hline Mailer & 18.5 & 392,856 & 18.8 & 13.9 & 4.3 \\
\hline \multicolumn{6}{|l|}{ CDR profile score } \\
\hline Low & 15.1 & 320,933 & 15.5 & 8.6 & 3.3 \\
\hline Medium & 32.7 & 693,830 & 33.3 & 21.4 & 3.7 \\
\hline High & 52.2 & $1,110,072$ & 51.2 & 70.0 & 7.7 \\
\hline \multicolumn{6}{|c|}{ Year of initial FMR decision } \\
\hline 1998 & 18.2 & 386,742 & 18.3 & 16.6 & 5.2 \\
\hline 1999 & 12.5 & 264,635 & 12.5 & 11.9 & 5.5 \\
\hline 2000 & 15.8 & 336,061 & 15.9 & 13.8 & 5.0 \\
\hline 2001 & 14.6 & 311,139 & 14.9 & 11.1 & 4.3 \\
\hline 2002 & 11.4 & 241,280 & 11.3 & 12.1 & 6.1 \\
\hline 2003 & 6.2 & 132,684 & 6.1 & 8.1 & 7.5 \\
\hline 2004 & 6.4 & 136,917 & 6.3 & 8.2 & 7.3 \\
\hline 2005 & 6.6 & 140,282 & 6.5 & 8.3 & 7.2 \\
\hline 2006 & 3.5 & 74,509 & 3.4 & 4.8 & 7.8 \\
\hline 2007 & 2.6 & 55,905 & 2.6 & 3.1 & 6.7 \\
\hline 2008 & 2.1 & 44,681 & 2.1 & 2.0 & 5.5 \\
\hline N & \multicolumn{2}{|c|}{$2,124,835$} & $2,003,363$ & 121,472 & \\
\hline
\end{tabular}

Source: Authors' calculations using Social Security administrative records

CDR continuing disability review, FMR full medical review, MINE medical improvement not expected, MIP medical improvement possible, MIE medical improvement expected, DI disability insurance. See text for full descriptions of the sample

continued). The estimated upper bound on the impact of a cessation on earnings above their potential benefit is also 45 percentage points; the impact on work activity above their pre-eligibility earnings is about 38 percentage points, all else equal.

Even though about half of ceased beneficiaries earned above the various earnings thresholds, few are able to maintain that level for all of the follow-up period. For example, only $37 \%$ had earnings in all follow-up years, and only $20 \%$ were able to maintain earnings above the annualized SGA level or the poverty threshold in the 5 years after program exit.

The aggregate statistics presented above mask the differential outcomes across a very heterogeneous target population. To provide context about how specific groups of ceased beneficiaries and recipients fare after the FMR, we present several of our earnings measures by various characteristics. ${ }^{17}$ We ran regressions similar to Eq. (1) for each group. The full set of outcomes and characteristics are available upon request. 


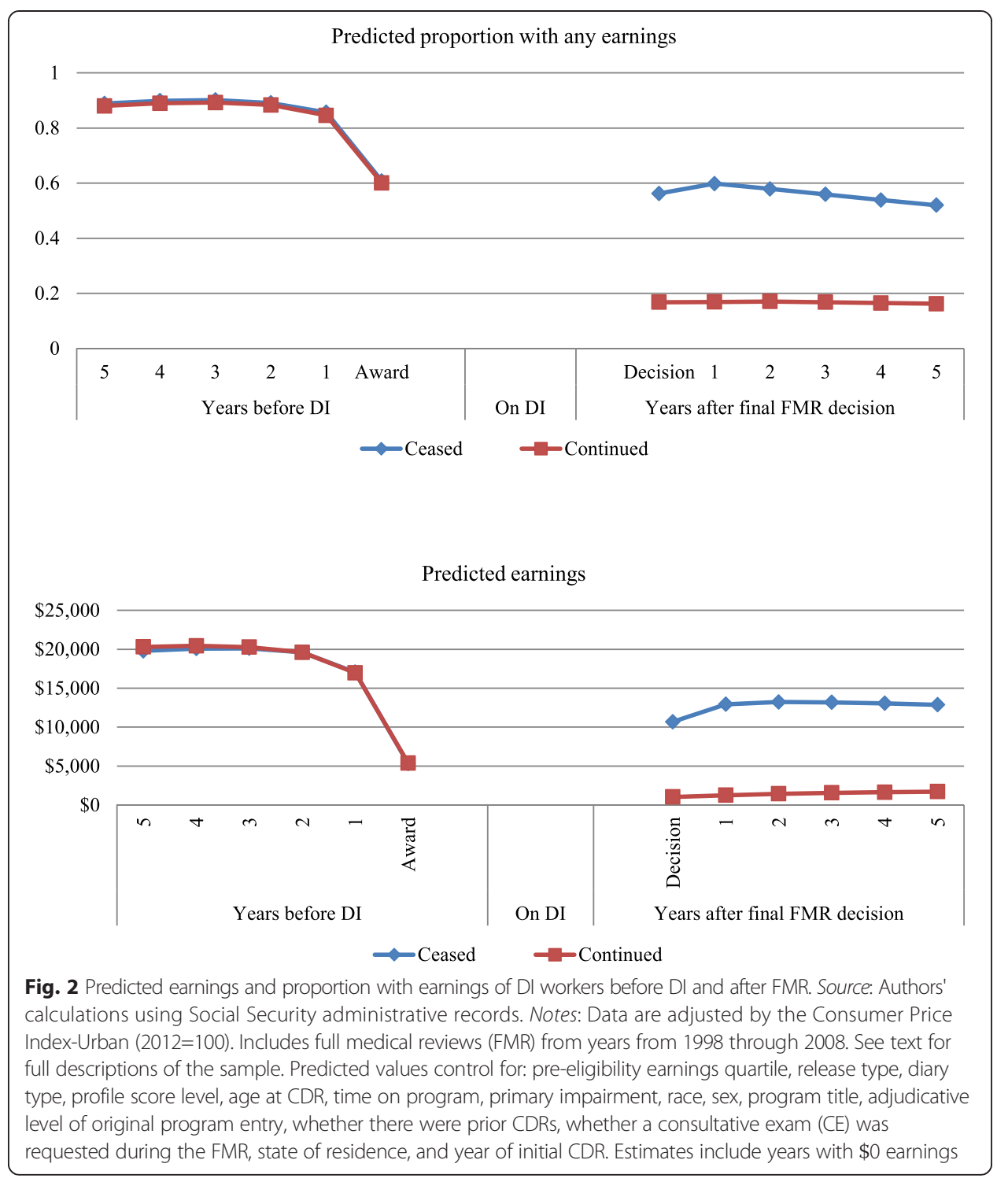

The impact of cessation on mean earnings is fairly constant in absolute terms across age groups (Fig. 3). However, former beneficiaries with neoplasms tend to earn the most (about $\$ 16,000$ per year) while those with schizophrenia and other psychotic disorders and intellectual disabilities have the lowest post-FMR earnings. The impact of cessation on earnings (and the proportion of former beneficiaries with earnings) is highest in magnitude for individuals with neoplasms or a disease of the musculoskeletal system and connective tissue (Fig. 4). Nearly $90 \%$ of ceased beneficiaries aged 18 to 30 have post-FMR earnings, though this percentage declines with age to below $60 \%$ for individuals aged 50 to 59. Those with schizophrenia and other psychotic disorders or an intellectual disability show the smallest relative impact of cessation on having earnings, due to a higher proportion of continued beneficiaries having earnings. The proportion of former beneficiaries with earnings in all follow-up years is notably lower and generally about half of the proportion with earnings in any year (Fig. 5). 
Table 3 Predicted 5-year average earnings of DI workers before and after FMR

\begin{tabular}{|c|c|c|c|}
\hline & Continued & Ceased & Impact $(\beta)^{d}$ \\
\hline Mean pre-eligibility earnings $(\$)^{a}$ & 19,518 & 19,331 & -188 \\
\hline Mean post-FMR earnings $(\$)^{a}$ & 1477 & 12,819 & 11,342 \\
\hline Ratio $(2 / 1)$ & 0.1 & 0.7 & \\
\hline Any post-FMR earnings (\%) & 26.7 & 69.6 & 42.9 \\
\hline In all follow-up years & 7.6 & 36.7 & 29.1 \\
\hline \multicolumn{4}{|c|}{ Percent with post-FMR earnings at or above } \\
\hline Pre-eligibility earnings ${ }^{b}$ & 9.9 & 48.3 & 38.4 \\
\hline In all follow-up years & 2.8 & 17.0 & 14.2 \\
\hline Potential benefit ${ }^{\mathrm{c}} \mathrm{c}$ & 7.9 & 52.6 & 44.8 \\
\hline In all follow-up years ${ }^{c}$ & 1.2 & 19.8 & 18.6 \\
\hline$S G A^{b}$ & 6.9 & 51.5 & 44.6 \\
\hline In all follow-up years & 1.1 & 19.6 & 18.5 \\
\hline Poverty ${ }^{b}$ & 7.4 & 52.2 & 44.8 \\
\hline In all follow-up years & 1.1 & 20.1 & 18.9 \\
\hline Full-time minimum wage ${ }^{b}$ & 6.0 & 49.1 & 43.1 \\
\hline In all follow-up years & 0.9 & 18.0 & 17.1 \\
\hline N & $2,124,835$ & & \\
\hline
\end{tabular}

Source: Authors' calculations using Social Security administrative records

Data are adjusted by the Consumer Price Index-Urban $(2012=100)$. See Fig. 2 for list of control variables

${ }^{a}$ Earnings are based on up to 5 years before DI eligibility and 5 years after the final FMR decision. If an individual had

fewer than 5 years of earnings in the respective period, then the mean is taken from however many years are available. Estimates include years with $\$ 0$ earnings

${ }^{b}$ Indicates if any year of earnings in the (up to) 5 years after the FMR (not including the year of the final decision) is

greater than or equal to the annualized threshold

${ }^{c} 118,195$ do not have PIA and are not included in the benefit estimates

${ }^{\mathrm{d}}$ All estimates are significant at the $<1 \%$ level

Thus far, we have looked at the overall earnings experiences of those who undergo a FMR and the experiences of selected demographic groups. An important question, however, is what the outcomes might look like if SSA were to increase the number of FMRs it conducts. For simplicity, consider a situation where SSA receives additional funding for CDRs but does not fundamentally alter the selection process or CDR rules-i.e., SSA simply conducts more FMRs with the same system of triage.

One way to consider what would happen is to assume that SSA would conduct more FMRs on beneficiaries further down the scale of cessation likelihood. That is, more MIPs and MINEs would receive FMRs, as would more people with medium or low CDR profile scores. If we assume the individuals in these groups would be moved into the FMR pool, and assume no substantial changes in the composition of these groups, our observed outcomes for these groups can be viewed as a good proxy for what may be expected. This would be an upper bound, since those not currently receiving an FMR in these groups would likely be in poorer health. Additionally, more individuals who received mailers would instead be directly released for an FMR. To the extent that those shifted into the direct release pool would be individuals who would have only received a mailer otherwise, outcomes would likely move toward those of the current mailer group.

For each of these groups, we see poorer post-FMR outcomes relative to those groups already most likely to receive a FMR (Table 4). Individuals who received mailers have 


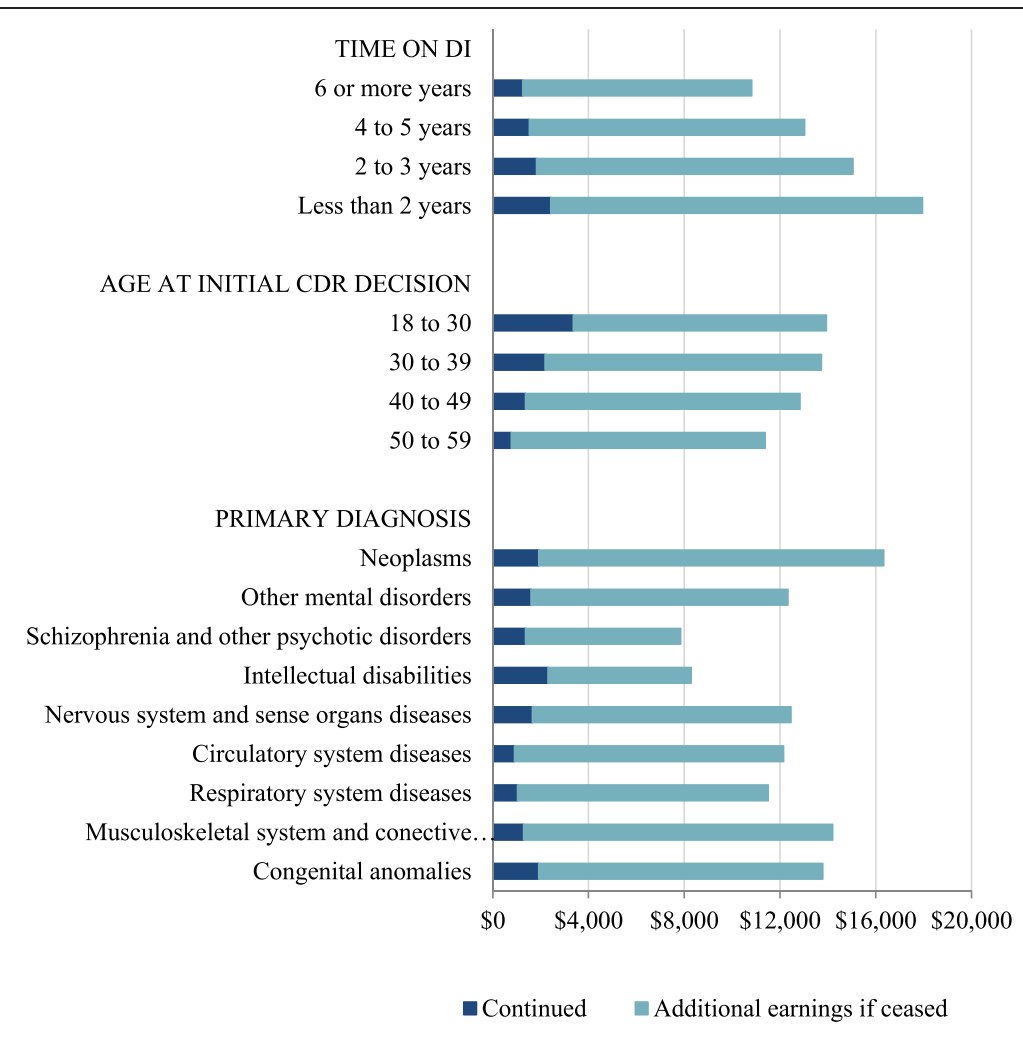

Fig. 3 Predicted post-FMR earnings of DI workers. Source: Authors' calculations using Social Security administrative records. Notes: Data are adjusted by the Consumer Price Index-Urban $(2012=100)$. Includes full medical reviews (FMR) from years from 1998 through 2008. See text for full descriptions of the sample. Earnings are based on up to five years before DI eligibility and five years after the final FMR decision. If an individual had fewer than five years of earnings in the respective period, then the mean is taken from however many years are available. See Fig. 2 for list of control variables. All estimates are significant at the $<1 \%$ level

lower earnings, are less likely to have any earnings, and less likely to have earnings above our earnings thresholds than those directly released for a FMR. Similarly, those with MINE or MIP diaries have worse labor market outcomes than those with MIE diaries, and those with low or medium profile scores perform worse than those with high profile scores in the labor market. The composition of these groups, particularly with respect to impairments, would likely change if SSA increased the number of CDRs in any given year as well as in the future as increased CDRs remove individuals from certain impairment groups from the beneficiary population and thus future years' CDR pool. Because we do not observe the full population eligible for a CDR, we cannot surmise exactly how such a shift would affect these results.

An alternative way to estimate the earnings outcomes of ceased beneficiaries under a policy of conducting additional CDRs is to compare outcomes across time periods when SSA had different levels of funding (Fig. 1). As the resources, staff, and funding available for FMRs varied over the study period, the post-FMR earnings outcomes have likely also varied. However, estimates on earnings outcomes are likely correlated with the overall economy and recent cohorts are likely substantially affected by the Great Recession. Without a way to differentiate between the effect of resources and the 


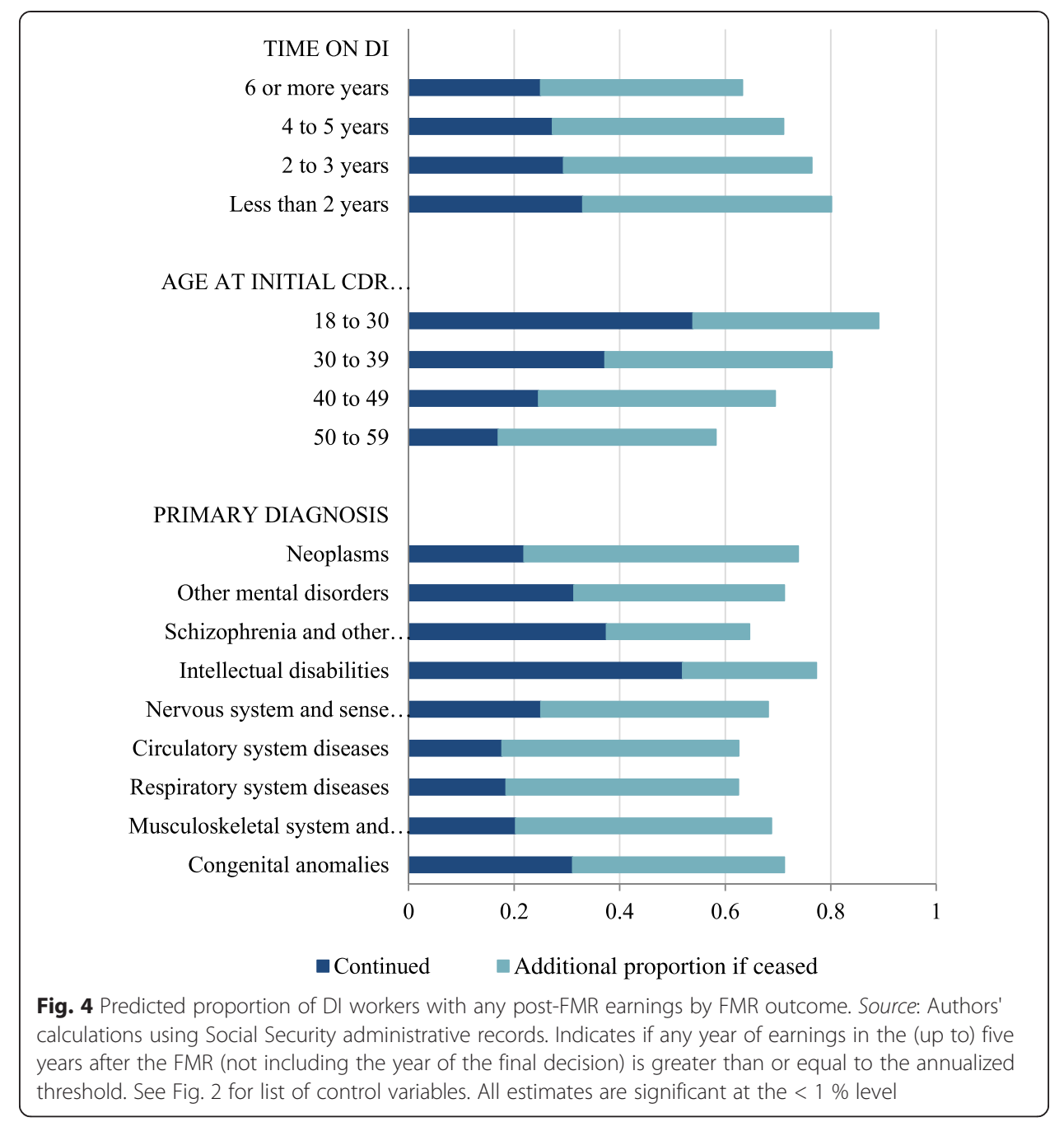

economy, we are unable to project any reasonable estimates of the pure effect of increased resources dedicated to CDRs. ${ }^{18}$

\section{Discussion and conclusions}

This paper presents estimated labor market outcomes for individuals ceased from disability program participation after FMRs and offers a glimpse of what might be expected if SSA increased the number of CDRs it conducts. Since our estimates are based on a specific segment of the CDR population, we caution the reader against drawing broad conclusions about implications for the entire CDR population. The majority of ceased beneficiaries have some earnings in the 5 years after a FMR cessation. If the Bound methodology holds, then the upper bound of potential effect on earnings for those on the exit margin is high-about 43 percentage points. However, earnings for ceased beneficiaries are generally low-average earnings for ceased DI workers are about $\$ 13,000$, compared to a national average of about $\$ 44,000$. About half earn at least as much as our definitions of their potential benefit, SGA, poverty, and the full-time minimum wage levels, but few maintain these levels of earnings for the entire follow-up period. 


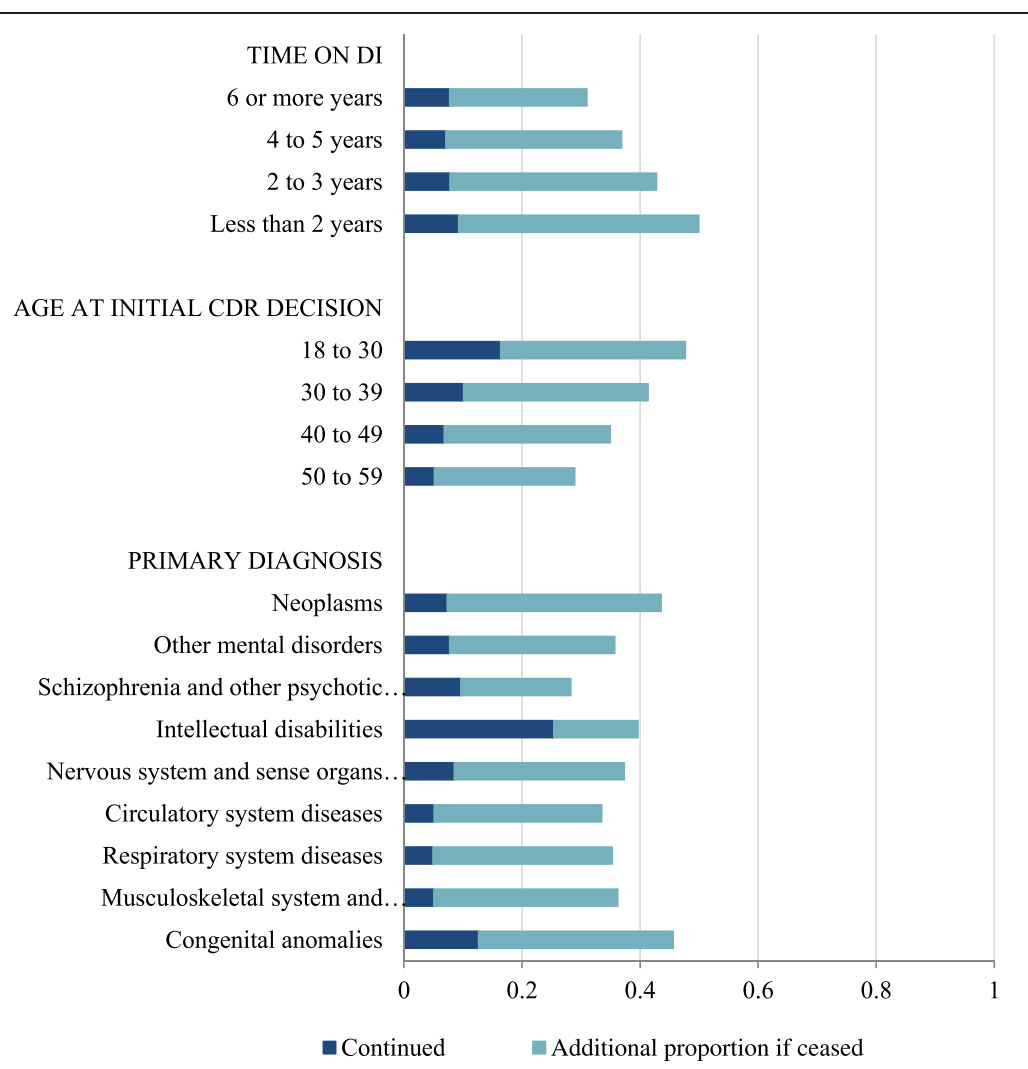

Fig. 5 Predicted proportion of DI workers with post-FMR earnings in all years by FMR outcome. Source: Authors' calculations using Social Security administrative records. Indicates if earnings in the (up to) five years after the FMR (not including the year of the final decision) are greater than or equal to the annualized threshold in every year. See Fig. 2 for list of control variables. All estimates are significant at the $<1 \%$ level

Bound's (1989) original study reported much lower employment for rejected male applicants in the 1970s (40-45\%) compared to our estimate for former beneficiaries (70 \%). ${ }^{19}$ von Wachter et al. (2011) also find much smaller potential impacts than we find. Recent research has used variation in the disability determination process to estimate the impacts of DI on employment for various groups. For example, Maestas et al. (2013) were able to identify applicants on the entry margin of the program and predicted a 28 percentage point higher employment rate for that group if they had not received benefits. French and Song (2014) also find much smaller effects. While our data do not allow such an analysis, it is one potential area of future research, given the medical CDR process follows the initial decision process. Even considering varying methodologies, the differences between the entry and exit margins appear large and especially important as SSA increases its program integrity activity.

Our population is generally defined as those that SSA determined, a priori, to have a high likelihood of cessation because their impairments may no longer preclude SGAlevel work. From that perspective, an upper bound of the impact of program exit on earnings of 40 to 50 percentage points could be viewed as small. Expanding program integrity operations (such as CDRs) may result in a lower a priori likelihood-of-cessation threshold used to target CDRs-more individuals that are less likely to be ceased would receive CDRs-leading to a higher rate of program return and lower average levels of work (measured by average earnings or earnings above the threshold measured in this 
Table 4 Predicted impacts on 5-year average earnings outcomes for DI workers by CDR characteristics

\begin{tabular}{|c|c|c|c|c|c|c|c|}
\hline & \multirow{2}{*}{$\begin{array}{l}\text { Mean post-FMR } \\
\text { earnings }(\$)^{\mathrm{a}}\end{array}$} & \multirow{2}{*}{$\begin{array}{l}\text { Any post-FMR } \\
\text { earnings }(\%)^{a}\end{array}$} & \multicolumn{5}{|c|}{ Post-FMR earnings at or above } \\
\hline & & & $\begin{array}{l}\text { Pre-eligibility } \\
\text { earnings }{ }^{b}(\%)\end{array}$ & $\begin{array}{l}\text { Potential } \\
\text { benefit }^{b}(\%)^{c}\end{array}$ & $\begin{array}{l}\mathrm{SGA}^{\mathrm{b}} \\
(\%)\end{array}$ & $\begin{array}{l}\text { Poverty } \\
(\%)\end{array}$ & $\begin{array}{l}\text { Full-time min. } \\
\text { wage }^{\mathrm{b}}(\%)\end{array}$ \\
\hline Total & 11,342 & 42.9 & 38.4 & 44.8 & 44.6 & 44.8 & 43.1 \\
\hline \multicolumn{8}{|c|}{ CDR release type } \\
\hline $\begin{array}{l}\text { Direct } \\
\text { release }\end{array}$ & 11,664 & 43.6 & 39.4 & 45.8 & 45.6 & 45.9 & 44.1 \\
\hline Mailer & 9303 & 37.7 & 31.5 & 38.1 & 37.9 & 38.1 & 36.5 \\
\hline \multicolumn{8}{|c|}{ CDR diary type } \\
\hline MIE & 13,304 & 45.8 & 40.8 & 48.0 & 47.9 & 48.2 & 46.5 \\
\hline MIP & 10,811 & 42.1 & 38.0 & 44.1 & 43.9 & 44.1 & 42.3 \\
\hline MINE & 8512 & 35.1 & 29.7 & 35.9 & 35.6 & 35.9 & 34.5 \\
\hline \multicolumn{8}{|c|}{ CDR profile score level } \\
\hline Low & 8620 & 36.9 & 29.7 & 35.8 & 35.6 & 35.7 & 34.1 \\
\hline Medium & 9732 & 41.8 & 34.5 & 41.1 & 40.6 & 40.8 & 38.9 \\
\hline High & 12,171 & 43.9 & 40.6 & 46.9 & 46.9 & 47.1 & 45.4 \\
\hline
\end{tabular}

Source: Authors' calculations using Social Security administrative records.

Note: Data are adjusted by the Consumer Price Index-Urban $(2012=100)$. Includes full medical reviews (FMR) from years from 1998 through 2008. See Table 3 for list of controls. All estimates are significant at the $<1 \%$ level

${ }^{\mathrm{a}}$ Earnings are based on up to 5 years before SSI or DI eligibility and 5 years after the final FMR decision. If an individual

had fewer than 5 years of earnings in the respective period, then the mean is taken from however many years are available. Estimates include years with $\$ 0$ earnings.

Indicates if any year of earnings in the (up to) 5 years after the FMR (not including the year of the final decision) is greater than or equal to the annualized threshold

${ }^{c} 118,195$ do not have PIA and are not included in the benefit estimates

paper) among those ceased. Previous work (Hemmeter and Stegman 2013) has found that about $20 \%$ of former DI workers return to the program within 8 years. However, if SSA's CDR operations are currently underfunded, there may be a backlog of individuals who have medically improved but have not received a CDR in recent years. If these individuals are similar to those currently ceased, we could see somewhat similar outcomes with increased funding (at least until the backlog is eliminated). ${ }^{20}$

Increased program integrity, while appropriate for Social Security from a fiduciary perspective, may also increase the number of people requiring other supports. Overall, our findings imply that a substantial percentage of former beneficiaries are able to reenter the labor force after their benefits cease; however, a not-inconsequential minority of those with earnings do not meet common thresholds of earnings sufficiency and are not able to maintain their earnings over time. Additionally, almost one quarter of former beneficiaries have no earnings after cessation, and few ceased individuals maintain employment above our measured earnings thresholds for the entire follow-up period. Given the high probability of return and the generally poor labor market outcomes of many ceased beneficiaries, analyses of the relationship between SSA's CDR policy and the broader social safety net may be in order. Others have shown that spousal employment, other government programs, and asset spend-down are ways some individuals cope with waiting for a DI award (Coe et al. 2014, Lindner 2013, Bound et al. 2003). Whether these sources of support are available after program cessation is unknown. Similarly, access to and use of health insurance has changed substantially in recent years. This may have improved individuals' health, resulting in an increased ability 
to work or willingness to work, and the impact of the Affordable Care Act on the employment of former beneficiaries is an important area for future research.

Because the eligibility thresholds for SSA's disability programs are strict, many of the individuals we study likely still have significant disabilities; our results do not provide any evidence on the broader health of these individuals. In exploratory analyses, we found that $53 \%$ of ceased former beneficiaries who returned to the programs did so with a primary impairment in the same impairment category. Whether this is attributable to a new complication for the same body system (such as an original impairment of chronic bronchitis and a new impairment of emphysema both recorded as a respiratory impairment) or a relapse of the original condition (such as a recurrence of cancer) is not readily identifiable in our data. Additionally, any change in diagnosis upon return may not represent a new impairment since some secondary or unrecorded impairments may have become more expressed. That is, the condition was always present but was not reflected as the "primary" impairment in SSA records. Regardless, further research is needed to understand the health dynamics of ceased beneficiaries.

When SSA expanded CDRs in the early 1980s, there were many allegations of SSA terminating benefits for individuals with severe impairments that may not have improved or for individuals who had been receiving benefits for a long period, which "raise[d] questions about how and why these people [were] being terminated, and the fairness of SSA's decisions" (p. 5, Ahart 1982). This led to a moratorium on CDRs and eventually led to the medical improvement review standard and other long-lasting program rules (Government Accounting Office, 1986). Additionally, about two thirds of those whose benefits SSA terminated in the early 1980s expansion eventually returned to the program (Government Accounting Office, 1989). If SSA plans to expand CDRs again, it is important to do so in a manner that is both legal and equitable. This paper highlights one area for tracking the well-being of ceased beneficiaries-earnings; prior work (Hemmeter and Stegman 2013) suggests another-program return. Keeping track of these outcomes could alleviate public concerns about CDR policy.

For current beneficiaries, the fear of losing benefits may dampen any incentives to return to work. Although individuals can appeal a FMR cessation and may return to the program, a determination that these individuals no longer have a work-limiting disability may provide a greater incentive to attempt returning to work. Our results, and those of Hemmeter and Stegman (2013) and Hemmeter and Gilby (2009), suggest one additional potential area for research: whether supports are necessary, and if so which ones, to help individuals ceased because of a FMR return to work. Identifying these supports could lead to longer-term financial savings for SSA and achieve societal goals of self-sufficiency for individuals with disabilities.

\section{Endnotes}

${ }^{1}$ Yearly awards for Social Security Disability Insurance (DI) worker benefits have more than doubled since the 1980s. The peak year of awards was 2010 with 1,026,988 DI worker awards. (Social Security Administration 2013b)

${ }^{2}$ Maestas and Song (2011) and Maestas and Yin (2008) examined the employment effects of DI in the context of conversion to the Old Age and Survivors Insurance (retirement) part of Social Security. Their exit margin is substantially different in that 
there is no expectation of medical improvement and less societal pressure to work. It also represents a pure income effect compared to what we analyze, which is the overall effect of the DI program.

${ }^{3}$ The DI program also provides benefits to children and spouses of worker beneficiaries under certain conditions. We do not include these beneficiaries, or their eligibility criteria, in our discussion and analysis.

${ }^{4}$ While much attention has been paid to the DI program, relatively little attention is given to the SSI program. This is unfortunate as the two should not be, but often are, conflated (Berkowitz and DeWitt 2013). Since both programs share a common definition of disability and administrative processes, changes or calls for increased scrutiny of one often affect the other.

${ }^{5}$ This section and the following largely draw from the study by Hemmeter and Stegman (2013).

${ }^{6}$ In FY 2008, the last year of our study population, about $90 \%$ of initial decisions for DI workers were continuations. In the same year, $59 \%$ of initial cessations for DI workers were appealed to the reconsideration level, with $70 \%$ of those overturned. Additionally, about $79 \%$ of DI workers with a cessation at the reconsideration level appealed in FY 2008; 49 \% were successful. (SSA 2013a)

${ }^{7}$ Diary dates for MIE cases are set for between 18 months and 3 years; MIP diaries are set for 3 years; MINE diaries are set for 7 years.

${ }^{8}$ About $9 \%$ of DI workers died during the 5-year follow-up period. In analyses not reported in the text, we limited the target population to those who survived the followup period; the results were very similar to those presented here.

${ }^{9}$ Most legal earnings are now subject to the Social Security tax. Additionally, we expect few beneficiaries in our study to earn over the taxable maximum. In some cases, the earnings on an individual's record may reflect delayed earnings from prior work rather than for current work.

${ }^{10}$ Treitel (1979) also used a 5-year average of earnings.

${ }^{11}$ We set earnings after death to missing. The results are very similar when we set earnings after age 62 (early retirement) or subsequent SSI or DI participation to "missing" to reduce the effect of future program participation.

${ }^{12}$ The loss of benefits may be seen by some as a loss of the potential support necessary to work. For example, there may be some individuals working below SGA using their benefits for car payments and other expenses necessary for work. This could, in theory, lead to a narrower earnings gap (or even a negative gap) between the ceased and continued individuals. However, the loss of benefits in this case would result in less work. Thus, our estimate of the earnings and employment levels of ceased beneficiaries would still be an upper bound, but the difference between the ceased and continued individuals would be biased. Because work by non-ceased individuals in our target population is uncommon, we do not think this substantially alters our hypotheses.

${ }^{13}$ Covariates include pre-eligibility earnings quartile, release type, diary type, profile score level, age at CDR, time on program, primary impairment, race, sex, whether concurrently receiving SSI and DI, adjudicative level of original program entry, whether there were prior CDRs, whether a consultative examination was requested during the FMR, state of residence, and year of initial CDR. 
${ }^{14}$ We do not adjust the DI benefit amount by worker's compensation because in some states, DI is offset by worker's compensation and in other states, worker's compensation is offset by DI. We also do not adjust for automatic deductions for Medicare; doing so assumes similar deductions for health insurance in the labor market, which may not be realistic. The results are very similar when we subtract Medicare Part B premiums from the potential benefit (in 2013 the monthly premium for Part B was \$104.90). The availability of similarly-valued (both in terms of objective price and subjective utility) may affect the types of employment our study population, who may still have high health costs, seeks or is able to find. We thank an anonymous referee for identifying this issue.

${ }^{15}$ These annualized thresholds generally follow the same path. However, we note that the minimum wage measure is above the SGA and poverty thresholds in all years. Up until the early 2000s, SSA changed the SGA level sporadically, resulting in periods of declining real value. Similarly, the Federal minimum wage changes sporadically, losing real value for several years at a time. The poverty threshold has regularly been adjusted for the cost of living since its inception. In 2012, the last year of earnings data in our analysis, annualized SGA was $\$ 12,120$; the poverty threshold was $\$ 11,170$; the full-time Federal minimum wage was $\$ 15,080$; and the potential FBR was $\$ 8,376$.

${ }^{16}$ In addition to the exclusions listed in the text, we also exclude the profile sample from our analyses due to the changing nature of the profile sample over time and because our intent is to present the outcomes for individuals who go through the "usual" CDR process, not the process used to validate the CDR process.

${ }^{17}$ How the local economic environment affects outcomes likely plays an important factor in the re-entry of these individuals into the labor force. Unfortunately, we are unable to determine where individuals live after the year of the FMR. While many likely remain in the same area, there is no good source of information on former beneficiary migration.

${ }^{18}$ Simple bivariate regressions between the funding level (in millions) for a fiscal year and the percent of that calendar year's ceased beneficiaries with earnings above the various thresholds in any year surprisingly yield significantly positive, although tiny, coefficients. However, we note that this very simple analysis does not control for other factors, including fluctuating economic conditions.

${ }^{19}$ Our estimated impacts for males and females are not substantially different.

${ }^{20}$ The Congressional Budget Office (2011) estimates a marginal return on investment of only about $\$ 3$ for every $\$ 1$ SSA spends on CDRs above current expenditures, which is consistent with the expectation that additional CDRs will result in fewer people remaining off the program (and SSI, Medicare, or Medicaid).

Competing interests

The IZA Journal of Labor Policy is committed to the IZA Guiding Principles of Research Integrity. The authors declare that they have observed these principles. The authors are employees of the Social Security Administration. 
References

Ahart GJ (1982) Statement before the senate committee on governmental affairs, subcommittee on oversight of government management

Autor DH, Duggan MG (2003) The rise in the disability rolls and the decline in unemployment. Q J Econ 118(1):157-206

Autor DH, Duggan MG (2006) The growth in the social security disability rolls: a fiscal crisis unfolding. J Econ Perspect 20(3):71-96

Ben-Shalom Y, Mamun A (2015) Return-to-work outcomes among social security disability insurance program beneficiaries. J Disabil Policy Stud 26(2):100-110

Berkowitz ED, DeWitt L (2013) The other welfare: supplemental security income and U.S. social policy. Cornell University Press, Ithaca, NY

Black D, Daniel K, Sanders S (2002) The impact of economic conditions on participation in disability programs: evidence from the coal boom and bust. Am Econ Rev 92(1):27-50

Borghans L, Gielen AC, Luttmer EFP (2014) Social support substitution and the earnings rebound: evidence from a regression discontinuity in disability insurance reform. Am Econ J Econ Policy 6(4):34-70

Bound J (1989) The health and earnings of rejected disability insurance applicants. Am Econ Rev 79(3):482-502

Bound J, Burkhauser R, Nichols A (2003) Tracking the household income of SSDI and SSI applicants. In: Polacheck SW (ed) Worker Well-being and Public Policy. Research in Labor Economics, vol 22. Emerald Group Publishing Limited, Bingley, UK, pp 113-158

Brucker DL (2015) Social capital, employment and labor force participation among persons with disabilties. J Vocat Rehabil 43(1):17-31

Burkhauser RV, Daly MC (2011) The declining work and welfare of people with disabilities: what went wrong and a strategy for change. AEl Press, Washington, DC

Burkhauser RV, Daly MC (2012) Social security disability insurance: time for fundamental change. J Policy Anal and Manage 31(2):454-461

Chen S, van der Klaaw W (2008) The work disincentive effects of the disability insurance program in the 1990s. J Econom 142(2):757-784

Coe NB, Lindner S, Wong K, Wu AY (2014) How do people with disabilities cope while waiting for disability insurance benefits? IZA J Labor Policy 3(1):1-27

Congressional Budget Office (2011). Letter to the Honorable John Boehner and the Honorable Harry Reid about CBO's analysis of the impact on the deficit of the Budget Control Act of 2011, as posted on the Web site of the House Committee on Rules on August 1, 2011, https://www.cbo.gov/publication/41626.

DeHaven T (2013) The rising cost of social security disability insurance. Policy Analysis. no. 733. Cato Institute, August 6

Dykacz JM (1998) Return of disabled-worker beneficiaries to the DI program: some insights from the new beneficiary followup. Soc Secur Bull 61(2):3-11

Dykacz JM, Hennessey JC (1989) Postrecovery experience of disabled-worker beneficiaries. Soc Secur Bull 52(9):42-66

French E, Song J (2014) The effect of disability insurance receipt on labor supply. Am Econ J Econ Policy 6(2):291-337

Goss SC (2013) Testimony by chief actuary from social security administration before the house committee on ways and means, subcommittee on social security

Government Accounting Office (1986) Social security disability: implementation of the medical improvement review standard. GAO/HRD-87-3BR

Government Accounting Office (1989) Social security disability: denied applicants' health and financial status compared with beneficiaries'., GAO/HRD-90-2

Hemmeter J, Gilby E (2009) The age-18 redetermination and postredetermination participation in SSI. Soc Secur Bull 69(4):1-25

Hemmeter J, Stegman M (2013) Subsequent program participation of former social security disability insurance beneficiaries and supplemental security income recipients whose eligibility ceased because of medical improvement. Soc Secur Bull 73(2):1-38

Hennessey JC, Dykacz JM (1993) A comparison of the recovery termination rates of disabled-worker beneficiaries entitled in 1972 and 1985. Soc Secur Bull 56(2):58-69

Karlström A, Palme M, Svensson I (2008) The employment effect of stricter rules for eligibility for DI: evidence from a natural experiment in Sweden. J Publ Econ 92:2071-2082

Lindner S (2013) From working to applying: employment transitions of applicants for disability insurance in the United States. J Soc Policy 42(2):329-348

Maestas N, Yin N (2008) The labor supply effects of disability insurance work disincentives: evidence from the automatic conversion to retirement benefits at full retirement age., University of Michigan Retirement Research Consortium Working Paper 2008-194.

Maestas N, Song J (2011) The labor supply effects of disability insurance: evidence from automatic conversion using administrative data. U Mich Retirement Research Center WP 2010-247

Maestas N, Mullen KJ, Strand A (2013) Does disability insurance receipt discourage work? Using examiner assignment to estimate causal effects of SSDI receipt. Am Econ Rev 103(5):1797-1829

Mann DR, Mamun A, Hemmeter J (2015) Employment, earnings, and primary impairments among beneficiaries of the social security disability programs. Soc Secur Bull 75(2):19-40

Moore TJ (2014) The employment effect of terminating disability benefits., NBER Working Paper 19793

Morton WR (2015) Social security disability insurance (SSDI) reform: an overview of proposals to manage the growth in SSDI rolls., Congressional Research Service

Nichols A, Mitchell J, Lindner S (2013) Consequences of long-term unemployment. The Urban Institute

Parsons DO (1980) The decline in male labor force participation. J Polit Econ 88(1):117-134

Parsons DO (1991) The health and earnings of rejected disability insurance applicants: comment. Am Econ Rev 81(5):1419-26

Schmulowitz J (1973) Recovery and benefit termination: program experience of disabled-worker beneficiaries. Soc Secur Bull 36:3-15

Social Security Administration (2009) Annual statistical report on the social security disability insurance program, 2008. Social Security Administration, SSA Publication no. 13-11826. SSA, Washington, DC 
Social Security Administration (2013a) Annual report of continuing disability reviews. Social Security Administration, Fiscal Year 2010. http://www.socialsecurity.gov/legislation/FY\%202011\%20CDR\%20Report.pdf Social Security Administration (2013b) Annual statistical report on the social security disability insurance program, 2012 Social Security Administration, SSA Publication no. 13-11826. SSA, Washington, DC

Social Security Advisory Board (2009) Statement on the supplemental security income program. Social Security Advisory Board, 2009

Staubli S (2011) The impact of stricter criteria for disability insurance on labor force participation. J Publ Econ 95(9-10):1223-1235 Stephens M (2014). Analysis of the estimated cost-effectiveness of conducting medical continuing disability reviews (CDRs) under five theoretical program integrity funding paths. Memo to Stephen C. Goss and Eli N. Donkar Treitel R (1979) Recovery of disabled beneficiaries: a 1975 followup study of 1972 allowances. Soc Secur Bull 42(4):3-23 von Wachter T, Song J, Manchester J (2011) Trends in employment and earnings of allowed and rejected applicants to the social security disability insurance program. Am Econ Rev 101(7):3308-29

Submit your manuscript to a SpringerOpen ${ }^{\circ}$ journal and benefit from:

- Convenient online submission

- Rigorous peer review

- Immediate publication on acceptance

- Open access: articles freely available online

- High visibility within the field

- Retaining the copyright to your article

Submit your next manuscript at $>$ springeropen.com 